Fecha de recepción: junio 2013 Fecha de aceptación: marzo 2014 Versión final: mayo 2015

\section{La transformación post-socialista y la cultura popular: reflejo de la transición en series televisivas de Serbia 1}

Vesna Trifunović * y Jovana Diković **

\begin{abstract}
Resumen: Nuestra intención en este estudio es examinar de qué modo el nuevo fenómeno social y la orientación de valores, que ha sido consecuencia el proceso de transición (desde 1989 hasta hoy), están reflejados en la producción televisiva de series (telenovelas) domésticas en la sociedad serbia. En cuanto a la particularidad de la transformación post-socialista que se ha desarrollado en dos fases en la sociedad serbia, se han escogido dos series televisivas para este análisis: Srećni ljudi (La Gente Afortunada) y Mile protiv tranzicije (Milo vs. la transición). La primera pertenece al período de la primera transición (1989-2000), mientras la segunda se puede situar en el contexto de la llamada segunda transición (2000 - actualidad). La primera serie describe el inicio de la transformación social y económica, es decir, el colapso de las empresas públicas y estatales, la señalización de su privatización y la aparición de los empresarios privados. La segunda, por otra parte, realiza una parodia de la extensa aglomeración de determinadas relaciones políticas y sociales que han cambiado y de los valores que representan los indicadores de la transición (establecimiento de la democracia liberal, la corrección política, la multiplicación de las ONG, la integración en la UE). La razón principal por la que se han escogido estas series de TV para el análisis es el hecho de que describen diversos aspectos de diferentes fases del período completo de la transformación post-socialista. Enfocándonos en esto, creemos que podemos analizar cómo se reflejan y se presentan las consecuencias dominantes de diferentes fases de la transición en uno de los medios de comunicación más importantes de la cultura popular actual.
\end{abstract}

Palabras clave: fases de transición - series de televisión - sistema de valores - sociedad serbia - transición.

[Resúmenes en inglés y portugués en las páginas 284-285]

${ }^{(*)}$ Investigadora del Instituto Etnográfico de la ASCA y doctoranda en la Facultad de Filosofía. Los campos de su interés son antropología del folclore, antropología de la medicina y antropología de la cultura popular.

${ }^{(* *)}$ Se licenció en el departamento de Etnología y Antropología de la Facultad de Filosofía de la Universidad de Belgrado. En este momento realiza un Doctorado en la Universidad de Zúrich, departamento de Antropología Social y Cultural. Sus intereses en gran medida se hallan en el campo de la antropología política. 


\section{Introducción}

Los medios de comunicación masiva, definidos como medios electrónicos e impresos destinados a la comunicación masiva (Spitulnik, 1993), y la cultura popular, que normalmente implica los artefactos culturales que son reconocidos por un porcentaje importante de la población (Lohof, 1972), son, sin duda, áreas inseparablemente relacionadas. Se puede notar que la cultura popular generalmente se difunde a través de varias formas de los medios de comunicación masiva, y puesto que un medio de comunicación también puede ser creación de mensajes de la cultura popular, no se debería considerar sin tener en cuenta el modo de su transmisión. El enfoque antropológico de la cultura popular también señala uno de sus aspectos importantes, que es la relación entre el creador y el consumidor. Esta relación implica mensajes muy extensos en cierto contexto socio-cultural, basado en unas competencias culturales comunes para algunas formas de la cultura popular (Žikić, 2010). En esta inmensa, rica y diversa área, las series de televisión se encuentran entre sus formas más ubicuas en la vida cotidiana. El hecho de que existan cadenas televisivas muy célebres, como Fox Crime o Fox Life, que están especializadas en transmitir precisamente series televisivas, indica que esta forma de la cultura popular es muy apreciada. Otra razón de su popularidad podría ser el hecho de que la televisión por sí misma es uno de los medios de comunicación masiva dominante y omnipresente. Es ampliamente aceptado que la televisión nos presenta una clase especial de los programas de entretenimiento que coinciden con las pretensiones del público. Este medio puede surtir efecto profundo en la sociedad y por lo tanto, en la manera en la que será aceptado e interpretado cierto contenido emitido. La televisión es la barrera y el provocador de los sentidos y placeres (Fiske, 2001). Una estadística reciente ha demostrado que en la sociedad serbia la gente pasa hasta cinco horas al día viendo la televisión. Por otra parte, las series de televisión, sobre todo los domésticos, son unos de los programas televisivos más vistos (las dos declaraciones según las investigaciones de AGB Nielsen Media Research).

En el contexto de la sociedad serbia, las series de producción televisiva doméstica siempre han tenido un papel importante, lo que confirma el estatus de 'cultas' que muchas de ellas han adquirido. Durante décadas existió una cultura común de familia reunida al frente de la televisión con el fin de ver su serie favorita. La gente memoriza y cita las declaraciones graciosas y recuenta situaciones interesantes y divertidas de estos programas televisivos. Algunas de estas han entrado en el campo del folclore serbio y se han convertido, por ejemplo, en parte de las bromas cotidianas. Además, las series domésticas más populares se han emitido varias veces y en diferentes períodos de tiempo, lo que significa que diferentes generaciones están familiarizadas con ellas. Por lo tanto, este tipo de programa representa una parte de la memoria colectiva de la gente en la sociedad serbia (Đurković, 2005).

Precisamente esta omnipresencia e importancia de las series domésticas hace de ellas un medio apropiado para comunicar varios mensajes sociales. Estas pueden tratar diferentes temas, pero algunos de los más populares a menudo siguen la vida de la gente común, con las acciones principales que normalmente ocurren en el círculo de la familia y en el lugar de trabajo. Estas series generalmente son realizadas como un reflejo de la vida cotidiana en cierto contexto social, con una leve, y normalmente cómica, dosis de crítica hacia los defectos, caracteres, relaciones y costumbres de la gente. La mayoría de estas está destinada 
a un público más amplio de lo común, la población que antes era de clase trabajadora, pero ahora generalmente pertenece a la clase media. Además de su notable papel divertido, las series televisivas tienen también un transfondo educativo, comercial o ideológico. Como tales, frecuentemente responden a la situación social actual y explican ese nuevo fenómeno social y orientaciones de valor. Observando las series televisivas domésticas entre dos procesos de transición, desde 1989 hasta la actualidad, podemos notar que los mencionados cambios de orientación, valores y la aparición de un nuevo fenómeno social han sido bastante obvios.

Para demostrar de qué manera se representan los principales indicadores de los nuevos procesos sociales, económicos, políticos y culturales de la transición en una de las formas más importantes de la cultura popular en la sociedad serbia, hemos escogido dos series televisivas que tuvieron niveles de audiencia bastante altos al momento de ser emitían. Debido a la especificidad de la transformación post-socialista que se ha desarrollado en dos fases en la sociedad serbia, se han escogido dos series televisivas para este análisis: Srećni ljudi (La Gente Afortunada) y Mile protiv tranzicije (Milo vs. la transición). La primera pertenece al período que corresponde a la primera transición (1989-2000), mientras la segunda se puede situar en el contexto de la segunda transición (2000-actualidad). La primera serie describe el inicio de la transformación social y económica, es decir, el colapso de las empresas públicas y estatales, la anunciación de su privatización y la aparición de los empresarios privados. La segunda, por su parte, realiza una parodia acerca de la extensa aglomeración de unas relaciones políticas y sociales cambiadas y de los valores que representan indicadores de la transición (el establecimiento de la democracia liberal, la corrección política, la multiplicación de las ONG, la integración en la UE). Aunque ambas series describen la vida de gente común y sus reacciones dentro de la existente situación socio-cultural, deberían especificar algunas diferencias entre. Estas diferencias se refieren a los tipos de los dos seriales: mientras el primero es el típico programa de TV que se centra en la vida de toda una familia, el segundo introduce un programa individual, que a través de sus monólogos graciosos medita sobre el nuevo fenómeno social que ha traído la transición. Una de las diferencias importantes que debería tenerse en cuenta es un cambio gradual desde el reflejo y la descripción de la situación social en la primera serie, hasta un punto de vista más crítico sobre la vida social y política cotidiana, en la segunda.

La existencia de dos etapas del proceso de transformación post-socialista en Serbia es la razón principal por la que se han escogido estas dos series televisivas para este análisis. Nuestra intención en este trabajo es estudiar de qué manera el nuevo fenómeno social y las orientaciones de valor se reflejan en la producción televisiva de las series domésticas en dos fases diferentes de la transformación post-social.

\section{El contexto histórico, político y social de las dos transiciones en Serbia (1989-2000 y 2000-actualidad)}

Durante las dos últimas décadas la sociedad serbia ha sido sometida al proceso de transición que generalmente implica la transformación del sistema socialista previo al nuevo sistema democrático-liberal. Esta transformación incluye cambios políticos, económicos, 
sociales y culturales, pero difiere en algunos aspectos de aquellos procesos similares que han ocurrido en otros países de Europa del Este. Como hemos indicado en la introducción, la principal diferencia se ve reflejada en dos fases sucesivas de transformación que son específicas para la transición serbia. Por lo tanto, es necesaria una breve recapitulación de las circunstancias históricas, sociales y políticas generales para entender el problema y la esencia de la transición en Serbia que empezó en 1989 y perdura hasta la actualidad. Al finalizar la Segunda Guerra Mundial, Serbia se convirtió en una de las seis repúblicas socialistas $^{2}$ que constituían la recién formada República Federal Popular de Yugoslavia, que fue, posteriormente renombrada como la República Federal Socialista de Yugoslavia. El régimen socialista, que fue establecido al mismo tiempo, estuvo encabezado por el líder Josip Broz Tito quien, debido a circunstancias históricas y políticas especiales, tomó un curso político que llevó a la ruptura con la Unión Soviética en el año 1948, y a la formación del Movimiento No Alineados, unos años más tarde. ${ }^{3}$ La importancia geopolítica fue, entonces, reconocida por los países occidentales, sobre todo por los EE.UU, con cuya ayuda económica Yugoslavia logró desarrollar un sistema especial que la diferenciaba de otros países comunistas. Así, el alto nivel de producción centralizada fue descartado, así como algunos obstáculos ideológicos que impedían la fundación de empresas de grupo o privadas. El principio autónomo se introdujo en las empresas con el fin de reforzar la influencia de los trabajadores sobre sus superiores, establecer una sociedad igualitaria y nacionalizar la industria. A diferencia de la mayoría de otros países socialistas, los campesinos podían conservar sus pequeñas propiedades. Por otra parte, el gobierno estatal seguía siendo autoritario, la democracia multipartidaria no existía, y la policía política e inteligencia eran extremadamente poderosas.

Gracias a la habilidades políticas de Tito, tanto el bloque oriental como el occidental se encontraban económicamente abiertos a Yugoslavia, cuyos productos eran comerciables en los países occidentales debido a los sueldos de los trabajadores orientales, y también eran bien recibidos en el Este gracias a su diseño moderno. Al mismo tiempo algunos países occidentales otorgaron préstamos altos. Por ejemplo, entre 1965 y 1981 la deuda externa de Yugoslavia aumentó 23 veces, y sólo entre 1974 y 1981, el Fondo Monetario Internacional, 16 países occidentales y aproximadamente 600 bancos otorgaron a Yugoslavia una suma de 1,6 mil millones de dólares (Antonić, 2004). Sin embargo, este dinero no fue invertido en una nueva producción, sino que en su mayoría fue utilizado para mejorar el nivel de vida de la población. El consumo se aumentó, los sueldos comenzaron a crecer y las inversiones se hicieron de acuerdo con los criterios políticos, y no económicos. El principal interés del régimen era emplear tanta gente como fuera posible y proporcionarles sueldos satisfactorios, mientras que la productividad de esos trabajadores no era tan importante y estaba descuidada (Antonić, 2004). Este tipo de sistema debía inevitablemente afrontar la crisis que ya había empezado a principios de los ochenta, siendo 1980 también el año en el que murió Tito. Las reformas que fueron introducidas en 1989 por el primer ministro de entonces Ante Marković, lograron revivir la economía con los primeros pasos de su liberalización e introduciendo el derecho al empresariado privado. Esto y la paralela legitimación del sistema multipartidario en 1990 indicaron la transformación cuyo objetivo principal era hacer de Yugoslavia el primer país de Europa del Este que fuera a unirse a la Comunidad Europea. 
La caída del comunismo en 1989 para muchos países de Europa Oriental conllevó ciertas reformas políticas, económicas y sociales estructurales, con el principal propósito de abolir los paradigmas políticos socialistas y transformar el sistema previo a una democracia liberal y de libre mercado. Pero Serbia ha tenido una reorganización institucional un poco diferente y retrasada.

Cuando recién empezó la ruptura de Yugoslavia, el líder político que desaprovechó tres años de pequeños, pero importantes éxitos de las reformas liberales que fueron dirigidas por el primer ministro Ante Marković, fue Slobodan Milošević, quien comenzó su carrera como un burócrata comunista. Su ascenso político tuvo inicio en 1987 en la octava sesión del Comité Central de la Liga de los Comunistas de Serbia. Él logró hacer frente a su padre político, Ivan Stambolić, y depurar el partido paso a paso, sobre todo su comité central y también el aparato estatal, de los políticos liberales y orientados hacia las reformas (Ristić 2008, 346). En 1989 fue elegido presidente de la República Federal de Serbia, y fue visto más como un líder nacionalista que como un líder ideológicamente adoctrinado. Al mismo tiempo Slobodan Milošević consolidó su poder político, sobre todo durante la crisis en la provincia serbia de Kosovo y Metohija, donde las relaciones multiétnicas entre la mayoría albanesa y la minoría serbia empezaron a deteriorarse desde principios de los ochenta. Por un lado, su destacado papel en estos conflictos fue reconocido por algunos de sus compañeros yugoslavos como el comienzo de la dominación nacionalista de Serbia en la Yugoslavia Federal. Por otro lado, para los ciudadanos y los votantes Milošević empezó a representar la encarnación de un nuevo, firme y carismático líder quien transformaría Serbia y también Yugoslavia y las llevaría hacia una consolidación política, económica y nacional más fuerte.

Al contrario de eso, Yugoslavia se desintegró definitivamente en 1991 cuando Eslovenia y Croacia declararon su independencia, lo que oficialmente se consideró como el desencadenante de la guerra entre las antiguas repúblicas: Serbia, Croacia, y Bosnia y Herzegovina. Yugoslavia se desmoronó en la peor guerra civil desde la Segunda Guerra Mundial y Slobodan Milošević fue uno de sus protagonistas principales. La disolución sangrienta de Yugoslavia confirmó una vez más la tesis de Adam Mihnjik acerca de que la última fase del comunismo es el nacionalismo. La guerra terminó con la firma de los Acuerdos de Dayton en 1995. A partir de entonces las relaciones regionales nunca se han restablecido completamente, debido a serias pérdidas humanas y materiales. Finalmente, de la disolución de Yugoslavia surgieron cinco estados nuevos: Eslovenia, Croacia, Bosnia y Herzegovina, Macedonia y República Federal de Yugoslavia que consistía en los actuales Montenegro y Serbia. Sin embargo, mientras las demás antiguas repúblicas yugoslavas intentaban curar las heridas de la guerra, recuperar su economía y establecer un nuevo orden político, Serbia se enfrentaba a un nuevo conflicto político en la provincia de Kosovo y Metohija. En 1999, debido a la política autoritaria de Slobodan Milošević hacia los albaneses de Kosovo y Metohija, se llevó a cabo una intervención militar de la OTAN contra Serbia, y Kosovo finalmente se convirtió en un protectorado internacional. 4 Ese acontecimiento influyó en la caída del régimen de Slobodan Milošević. Desde 1989 hasta su caída en el 2000 su régimen suprimió sucesivamente todas las libertades políticas, construyó un estado policial que actuaba contra sus ciudadanos, mantuvo el sistema de economía centralizada, las empresas eran de propiedad del Estado, y, en general, consolidaron un sistema político autoritario 
en forma de una democracia de fachada.

El período de la primera transición corresponde al período en el que dominó el régimen de Slobodan Milošević desde 1989 hasta 2000. Debido a las razones mencionadas anteriormente, este período también es conocido como la "transformación bloqueada". Además de los factores políticos, se caracteriza por la existencia paralela de las empresas estatales y privadas, que fueron liberadas de las obligaciones socialistas, pero mantuvieron las formas socialistas de propiedad (Kovačević 2006; 2007; Lazić and Cvejić 2004). La transformación bloqueada causó el retraso del desarrollo de la economía de mercado y el colapso gradual de las empresas estatales que fueron cedidas a las privadas (Kovačević 2006). Por otra parte, durante este período Serbia experimentó algunas de las transformaciones post-socialistas por las que muchos países de Europa Oriental ya habían pasado (Verdery 1998). Eso puede apreciarse particularmente en los cambios internos del sistema partidario; formación del estado y sus fronteras de acuerdo con la afiliación étnica y el aumento del nacionalismo como un tipo de capital político (Verdery 1998: 292 - 297); y en el comienzo de la política y economía de privatización (muy a menudo de fachada) y el proceso de restitución que nunca ha sido terminado. Sin embargo, la sociedad serbia tuvo que esperar transformaciones post-socialistas cruciales y estructurales que empezaron con la segunda transición.

El año 2000 representa el comienzo de la nueva era política de Serbia cuando la Coalición Democrática (DOS) estableció el primer gobierno democrático. Tremendos cambios sucedieron tanto en el ámbito del sistema político como en la organización económica. La democracia liberal, la economía orientada hacia el libre mercado, libertades políticas y civiles, el imperio de la ley, al igual que afiliación a la Unión Europea, han sido proclamados como principales objetivos de varios gobiernos desde el año 2000.

Por lo tanto, la segunda transición desde 2000 hasta hoy se conoce también bajo el nombre de "transformación desbloqueada" o atrasada (Kovačević 2006). Metafóricamente hablando, el muro de Berlín cayó en Serbia en 2000. No obstante, este proceso, al igual que en muchos países de Europa del Este, no ha ocurrido sin complicaciones. Los principales obstáculos de las reformas actuales son los problemas estructurales heredados del régimen socialista anterior como la corrupción, la criminalidad, numerosos conflictos legales y políticos no resueltos, y la élite política socialista que en gran parte todavía está representada por importantes figuras políticas o económicas (como tycoons - magnates). Por otra parte, ha habido varios gobiernos democráticos desde 2000 y ninguna consistencia en la conducta y la aplicación de las reformas. Esto está especialmente relacionado con diferentes ejemplos de privatización, inversiones extranjeras y domésticas y problemas que surgieron por falta de la Ley de Restitución (véase Naumović, 2006).

Según la opinión pública en Serbia los cambios transicionales en su totalidad no parecen prometedores (Mihailović 2010). Por ejemplo, una encuesta sobre los resultados de los cambios democráticos que fue realizada en 2005 muestra que $44 \%$ de los ciudadanos serbios piensa que todo sigue igual, $26 \%$ opina que los cambios han empezado, mientras $17 \%$ piensa que esto es el comienzo del deterioro de Serbia (Mihailović, 2010: 22). Además, el $64 \%$ de los ciudadanos opina que las condiciones económicas y políticas generales son insoportables (Ibid). Después de una estabilización relativa de nuevas divisiones políticas y los problemas estatales ardientes, como el asunto de Kosovo, el tema principal de la 
siguiente encuesta que fue realizada desde 2006 hasta 2010 fue sobre los resultados de la privatización. Puesto que la mayoría de los ciudadanos ha experimentado la privatización, el 44\% piensa que la privatización no es "nada más que un robo", el 27\% cree que es necesaria, pero que se ejecuta de una manera completamente errónea, mientras que solo $3 \%$ de los ciudadanos apoya la privatización actual (Ibid: 25).

Conforme a lo arriba mencionado, se puede concluir que la dificultad de ambas transiciones es uno de los asuntos más importantes de la sociedad serbia actual. Las series domésticas que han sido grabadas desde 1989 hasta hoy, y que encajan en el género del realismo social, expresan la esencia de la dificultad, y de manera directa o indirecta tratan problemas que conciernen a todos, o por lo menos a la mayoría de la sociedad. Por lo tanto, la popularidad de estas series, tal como creemos nosotros, depende de su variedad y del éxito que tienen al burlarse de los problemas sociales más delicados y de los fracasos del sistema. Al mismo tiempo, estas pueden ser indicadores de los cambios sociales, y también factores de emancipación, por otra parte. Es por eso que las series aquí se analizan no sólo como una forma entretenida, sino también como indicadores de las modificaciones políticas, sociales y culturales que han sucedido en la primera y en la segunda transición.

\section{Serie televisiva La Gente Afortunada y la primera transición}

El período de los noventa en la sociedad serbia normalmente se relaciona con la predominante decadencia social y cultural, la guerra civil y la inseguridad económica que hizo que la mayoría de la población apenas pudiera sobrevivir. Estos hechos, además de otras influencias, han llevado a algunos autores a la suposición que la producción doméstica de las series televisivas durante este período no trajo nada especial, nuevo ni que merezca la pena recordarlo (véase por ejemplo: Đurković, 2005). Sin embargo, las afirmaciones de este tipo son definitivamente polémicas si consideramos los títulos de las series televisivas que fueron hechos y emitidos en aquellos tiempos. ${ }^{5}$ Durante los noventa se realizaron unas nueve series de TV, tres de las cuales alcanzaron gran popularidad. ${ }^{6}$ Una de ellas fue La Gente Afortunada, dirigida por Aleksandar Đorđević y Slobodan Šuljagić, que fue emitida en dos temporadas desde 1993 hasta 1995, y repetida varias veces, años más tarde. Según varios indicadores, esta es la típica clase de serie de producción televisiva doméstica. Fue emitida en la televisión nacional en el horario de mayor audiencia, los domingos por la noche, a las ocho o a las nueve, de la misma forma que otras series del mismo género que antes habían alcanzado gran popularidad. Como ya se ha mencionado, el tema común de este tipo de series es la vida de la gente común y sus familias que se enfrentan a los problemas cotidianos y los manejan, pasando por diferentes situaciones y acontecimientos, generalmente humorísticos. La importancia de este tema en particular puede clasificar estas series en el género del realismo social. Según Marion Jordan, este género supone una narración de unos acontecimientos personales importantes para los personajes principales, pero que también afectan a los demás en menor medida. A pesar de que estos acontecimientos aparentemente tratan de problemas sociales, ellos normalmente tienen como uno de sus intereses centrales la adaptación de la gente a las condiciones de vida. Los caracteres son representados de una manera verosímil en cuanto a 'la normalidad' de sus hogares, 
familias, amigos, y los escenarios son lugares comunes reconocibles (como se ha mencionado antes: el círculo de la familia o lugar de trabajo). El tiempo está situado en 'el presente’ y con respecto al estilo, este sugiere una visión completa de la realidad (Jordan, 1981). Todo esto indica que las series televisivas del mismo tipo no comparten sólo el mismo tema, sino que también tienen una fórmula parecida, es decir, un sistema convencional de estructuración, por lo que vamos a utilizar el concepto de fórmula de Cawelti como principal marco teorético para el análisis del material mencionado. Según este autor, la fórmula refleja preocupaciones y necesidades particulares del tiempo en el que el producto cultural es creado y del grupo que lo ha creado. Esto significa que el análisis de la serie La Gente Afortunada nos da la oportunidad de comprender mejor el sentido de la realidad predominante y las orientaciones de valor que fueron presentadas por medio de la televisión durante el período llamado la primera transición. Esto se puede lograr prestando atención a la manera en la que fueron representados aquí los elementos importantes y la realidad transicional. Uno de esos elementos era la existencia paralela de las empresas estatales y privadas, $\mathrm{y}$ en estas series podemos encontrar diferentes conceptualizaciones y evaluaciones de ellas.

Algunas de las circunstancias importantes que ocurrieron durante el período de la transformación bloqueada, concretamente el retraso del desarrollo de la economía de mercado y el colapso gradual de las empresas estatales que cedieron el lugar a las privadas, se reflejan en esta serie de un modo específico: a través de la confrontación de los personajes principales con las circunstancias de la vida, generalmente en sus lugares de trabajo. El deterioro de las empresas estatales, por ejemplo, está representado a través de sus relaciones disfuncionales con otros empleados, quienes por otra parte comparten la indolencia para el trabajo y la falta de respeto hacia la autoridad, lo que en su mayor parte es causado por los bajos salarios y un declive material general.

La razón de este tipo de representación se debería buscar en la perspectiva diacrónica, o sea, en las condiciones sociales que existían antes de la primera transición y que crearon ciertas conceptualizaciones culturales relacionadas con la relación entre el empleador y el empleado. Conforme a estas conceptualizaciones el empleador antes representaba el estado personificado, la sociedad y el sistema con la obligación de proporcionar recursos económicos a sus empleados, quienes, por otra parte, estaban sobreprotegidos por la ley laboral (Žikić, 2007). Esto produjo un gran número de trabajadores indolentes quienes no dieron mucho a cambio a sus empleadores inmediatos - las empresas estatales. Esto fue muy bien reflejado en el dicho del período de autogobierno socialista: "Nadie puede pagarme tan poco como yo puedo trabajar" (Žikić, 2007: 57). En estas circunstancias la sociedad entró en período de la primera transición cuando la obligación mencionada ya no se cumplía, lo que causó salarios mínimos y declive material de los empleados de las empresas estatales. Estas condiciones sociales están reflejadas en la serie televisiva a través de la mencionada representación de los trabajadores como indolentes, irrespetuosos, corruptos e insatisfechos con su posición, lo que en conjunto creó una imagen de las empresas estatales como sumamente disfuncionales. Se debería notar que esta imagen de las empresas estatales se podía encontrar también en las series previas del mismo género. Sin embargo, cuando se relaciona con la representación de los empresarios privados quienes empezaron a aparecer intensivamente en este período, esta imagen se convierte en 
parte de un panorama más amplio que refleja las conceptualizaciones sociales predominantes y dilemas del período en cuestión. Empresarios, propietarios de varias agencias y nuevos ricos son verdaderos personajes transicionales y se presentan por primera vez en una serie televisiva doméstica. Es importante notar que los personajes centrales de esta serie no vienen de estos grupos sociales, sino que son gente 'común' de la clase media que se ve obligada a encontrar caminos alternativos para ganarse la vida, y a partir de ahí entran en un tipo de contacto con 'el nuevo mundo de empresarios privados'. Esto significa que los empresarios privados están representados aquí a través de los ojos de los personajes principales de la gente común, lo que es comprensible teniendo en cuenta que el mundo televisivo se centra más en la clase media, proporcionando su contenido típico y posición desde su punto de vista (Fiske, 2001). Su representación es holística y abarca su personalidad, su vida privada y profesional. Sumariamente, la imagen de los empresarios privados es negativa en su totalidad. Existen dos tipos de caracterización: están descritos o como ordinarios, incultos, codiciosos, corruptos y estafadores indignos, o como figuras ricas y poderosas, pero paranoicas, todos ellos con unas relaciones muy disfuncionales con sus parientes y familias. Su vida profesional es aparentemente exitosa, lo que se refleja en sus altos ingresos y calidad de vida, pero en realidad su vida es insegura, relacionada con la mafia y éticamente problemática.

Sin embargo, los empresarios privados no eran una absoluta novedad en la primera transición en la sociedad serbia. Los empresariados privados ya habían existido antes de que el proceso de transición empezara puesto que el sistema legal de La República Federal Socialista de Yugoslavia reconoció y aceptó algunas de sus formas. Por otra parte, este tema en aquel tiempo no atraía el interés público tanto como durante la década de los noventa (Žikić, 2007). La imagen de los empresarios privados en la serie La Gente Afortunada en parte deriva de las condiciones sociales bajo las cuales se desarrollaba la primera transición, como la guerra civil, aislamiento económico, embargo, economía gris, hiperinflación, intensificación de la criminalidad y enriquecimiento de aquellos que participaron en estas actividades. Todo esto produjo dudas sobre la posibilidad de conseguir riqueza material de un modo legal y socialmente aceptable. No obstante, esta imagen de los empresarios también dependía del hecho que la mayoría de la población antes de que la transición empezara no entendía completamente cómo funcionaba exactamente el negocio privado. ${ }^{7}$ En otras palabras, los empresarios privados estaban situados, en el sentido cognitivo, fuera del sistema común, lo que causó cierta desconfianza hacia ellos (Žikić, 2007). Teniendo todo esto en cuenta, es hasta cierto punto comprensible por qué ellos están representados de esta manera en la serie, aunque en realidad hubo gente que intentaba tener éxito en los negocios privados dentro de los marcos legales (véase: Naumović, 2006). Por otra parte, las empresas estatales y sus empleados, como pudimos ver, tenían el mismo trato negativo aunque estas eran categorías familiares. Para explicar esto, podemos observar el período de transición como tiempo de liminalidad social, cuando son violadas todas las normas, y todo el sistema cambia con el fin de que se establezcan nuevos valores y normas. Esto significa que los sistemas comunes y formas anteriores ya no son aceptables, así que la representación de las empresas estatales y sus empleados aquí se podría interpretar como un modo de criticar ese sistema y rechazarlo como obviamente imperfecto y disfuncional. Sin embargo, debido a las mencionadas condiciones y conceptualizaciones 
sociales, el empresariado privado no pudo ser aceptado como una alternativa inmediata. Todo esto hizo que la sociedad buscara su propia respuesta a la situación existente y ofreciera aceptables formas de vivir y maneras de enfrentarse a la vida en estas circunstancias especiales, que se presentan por medio de los personajes principales de la serie de TV. Ellos están representados como personajes que se balancean entre el sector privado y el público, tratando de mantener a sus familias. Hacia el final ellos son valorados positivamente dado que, a diferencia de los empresarios y empleados de las empresas estatales, lograron conservar valores como la dignidad, la honestidad, la moral alta y lo más importante según esta serie -la familia, a pesar de los tiempos difíciles y las grandes tentaciones. El título de la serie La Gente Afortunada, que hace referencia a esos personajes principales se puede comprender muy bien en este preciso discurso. En resumen, lo que se presenta en esta serie no es sólo la imperfección del sistema previo y los prejuicios sobre su alternativa desconocida, sino también el esfuerzo por generar un balance entre la vida privada y profesional y la preservación de valores éticos en los tiempos peculiares de la transformación social. Puesto que la prosperidad económica no era posible para la mayoría de la población durante este período, otras formas del éxito social fueron enfatizadas y presentadas al público televisivo, como el respeto y la vida de acuerdo con normas y valores éticos antes mencionados. Estas fueron las convenciones discursivas durante la primera transición de la sociedad serbia, de acuerdo con las cuales el predominante sentido de la realidad fue construido y presentado por medio de televisión y a través de una forma importante de la cultura popular como lo es una serie televisiva.

Por otra parte, está claro que el aspecto político del tiempo turbulento de los noventa se descuidó bastante en esta serie de TV. Esto no ocurrió sólo por las delicadas circunstancias socio-políticas que ya se han mencionado (ej. guerra civil, relaciones étnicas deterioradas, sistema autoritario), sino también porque esta serie fue emitida en la televisión nacional que se encontraba bajo la influencia directa del régimen de Milošević. A diferencia de esto, la siguiente serie de TV que será analizada aquí, trata en gran medida el aspecto político de la sociedad serbia. Esta diferencia se presenta debido al nuevo contexto social de la transformación atrasada en que fue realizada dicha serie, y también a las connotaciones específicas del canal televisivo que lo emitía.

\section{Milo vs. la transición en la segunda transición}

"Transición - la enfermedad más reciente de nuestra sociedad" Milo de Čubura (Barrio de Belgrado)

Milo vs. la transición es una serie de TV serbia dirigida por Radivoje Andrić. Fue emitida por primera vez en 2003 en la cadena B92, que durante la época de Slobodan Milošević fue un medio de comunicación de oposición, pionero en reportajes anti-guerra, anti-nacionalista y anti-régimen. Después de los cambios democráticos en 2000, la televisión B92 empezó a producir y emitir el programa de manera abierta y sin ningunas restricciones, alcanzando altos niveles de calidad de diferentes formas televisivas como documentales ${ }^{8}$, 
noticias, programas de debate políticos, programas de entretenimiento, etc. En 2006 la Agencia República de Radiodifusión le concedió la frecuencia nacional a la televisión B92. Desde su creación hasta la actualidad, esta televisión ha sido consistente en promocionar sus principales orientaciones de valor que están expresadas de un modo pro europeo, democrático y cosmopolita, continuando con las observaciones críticas del trabajo de diferentes gobiernos de la nueva época democrática de Serbia.

La transmisión de Milo vs. la transición concuerda con varios acontecimientos políticos importantes. Antes que nada, inmediatamente después del asesinato del primer ministro Zoran Đinđić 9 en 2003, el Estado entró en un tipo de vacío, intentando detener y prevenir el crimen, los lobbies y procesar a los asesinos del primer ministro, mientras que los asuntos exteriores (integraciones europeas y otros cambios transicionales) fueron dejados de lado. En 2004 se formó un nuevo gobierno, con Vojislav Koštunica, líder del Partido Democrático de Serbia (DSS), como primer ministro. Koštunica permaneció en sus funciones hasta 2008 (cumplió dos mandatos como primer ministro, el primero desde 2004 hasta 2007, y el segundo desde 2007 hasta 2008). Durante este período de tiempo, Koštunica y su coalición gobernante contribuyeron en gran medida al descenso económico y político del país y al estancamiento debido al bloqueo de todos los caminos principales de los procesos transicionales de Serbia, anulando prácticamente todos los efectos positivos y reformas logrados por el gobierno de Đinđić. El partido de Koštunica, conservador y nacionalista pero con un programa político democrático, se comprometió sólo de nombre con la UE y a las integraciones europeas, mientras que en la práctica la política oficial del Estado estaba fomentando una política de "fuerte euroescepticismo" (Taggart y Szczerbiak, 2002; Kopecky y Mudde, 2002). ${ }^{10}$ Esto fue más que obvio en la esfera de la política exterior donde el gobierno de Koštunica cuestionaba la legitimidad y relevancia del Tribunal Internacional de La Haya. ${ }^{11}$ Impulsando el curso principal de la política del estado hacia Este, él abogaba abiertamente por la intimidad política con Rusia y China, mientras que en la política doméstica, la lucha por conservar Kosovo, la (ex) provincia autónoma de Serbia, bajo la soberanía de Serbia se convirtió en el imperativo del Estado. El eslogan que en pocas palabras y efectivamente expresa la esencia de la política oficial del Estado se encuentra en la declaración de Koštunica del año 2008 en la que expresa que "el ingreso a la UE no está más en los planes de Serbia” (ver más en http://en.wikipedia.org/ wiki/Vojislav_Koštunica). Tal ambiente político general también aumentó la desconfianza hacia la UE y las integraciones europeas, y finalmente, produjo resultados muy negativos en cuanto a la transición serbia.

Cuando la serie de TV Milo vs. la transición fue emitida por primera vez en la televisión B92 en 2003, logró gran éxito, superando todas las expectativas. Las graciosas y divertidas observaciones sobre la transición del protagonista Milo de Čubura (Čubura es uno de los barrios más antiguos de Belgrado, que es la capital de Serbia) se convirtieron en parte de las bromas y réplicas cotidianas. Muy pronto la popularidad de esta serie, sobre todo de su protagonista, fue transmitida a varios jingles de TV, canciones, y hasta a comerciales. ${ }^{12}$ Además, la propia forma del programa demuestra su peculiaridad. Por primera vez en Serbia apareció el llamado 'programa unipersonal', en forma de monólogos humorísticos dentro de un capítulo de 15 minutos que se emitía cada sábado a las 11 de la noche. ${ }^{13}$ 
En los primeros capítulos se presenta a Milo y el ambiente de su casa a los espectadores. Él es un hombre casado de mediana edad, que vive con su esposa y un pequeño hijo. Siempre está insatisfecho y sin dinero. Vive en un pequeño departamento con una decoración típicamente socialista y con recuerdos materiales de la antigua Yugoslavia como una estatua de Tito, postales de la costa croata, bandera de Yugoslavia etc. Parece que el ambiente de su casa ha sido decorado de esa manera adrede, teniendo en cuenta que el director de la serie evidentemente quería jugar de manera simbólica con la aún fuerte presencia de 'titostalgija' (Tito nostalgia) y de románticos recuerdos de la antigua Yugoslavia socialista entre gran parte de la población mayor y de mediana edad en Serbia. Por otra parte, su departamento es como una verdadera cámara de productos tradicionales serbios, como los ajos encadenados contra la maldición, pequeños pimientos rojos y secos para decoración, una gorra de hombres tradicional serbia (šajkača), un traje, etc. Una de las peculiaridades de Milo es una pareja de pequeños zapatos de piel tradicionales conocidos como 'opanci', los cuales bambolea delante de sus ojos como un reloj de hipnotizador cada vez que una noticia le altera.

Milo vs. la transición fue intencionadamente inventado como una ironía y como una obvia parodia de un serbio estereotipada. En muchos aspectos Milo personifica la mentalidad serbia estereotipada (negativa): maldad, grosería, embriaguez, desconfianza, y sobre todo afecto hacia las teorías de conspiración. El personaje de Milo es interesante -representa una combinación de la persona nacionalmente muy consciente, pero con fuerte herencia socialista en cuanto a las costumbres retóricas y laborales. Como dijo el famoso publicista serbio Teofil Pančić

Milo es un feliz y orgulloso sucesor de la anterior cultura cotidiana del socialismo auto-gobernante, pero sólo en esos aspectos que a él le agradan, que hoy tienen 'valor de uso'. Por otra parte, él 'se concienció nacionalmente’ hace diez o quince años, rechazó los engaños e injertó una nueva narración dominante sobre el antiguo código cultural auto-gobernante, la de nación y tradición, y sobre todo de nuestra peculiaridad en el cosmos (Pančić, 2005).

Por lo tanto, Milo representa un personaje transicional verdadero no sólo por las cosas que dice y hace, sino por su reorganización mental y cambios de valores, ideologías, y su auto-ubicación en el periodo en el que dominan fuertes cambios sociales, políticos y económicos. Él personalmente es la metáfora de la transición. Él es el everyman de una época y "el reflejo del dominante eclecticismo conformista" (Pančić, 2005).

La crítica social, es decir, la crítica de la mentalidad serbia empacado en forma de ironía auto-burladora, es la fórmula de la serie Milo vs. la transición en el sentido en el que lo define Cawelti. "Una fórmula es un sistema convencional que sirve para estructurar productos culturales" (Cawelti, 1969: 386). Él además explica que estas fórmulas, debido a "su relación tan cercana con la cultura y el período particulares, suele tener un repertorio de argumentos, personajes y escenarios mucho más limitado" (Cawelti, 1969: 387- 388). Si aplicamos su definición a esta serie de TV, su fórmula, en términos generales, sería subordinada a la segunda transición y a sus consecuencias. Antes que nada, la transición supone 
una adaptación a las nuevas y cambiadas pautas socio-culturales, políticas y económicas. En el contexto de Serbia esto significa adaptarse a la democracia liberal, al imperio de la ley, y también al papel de las ONGs en la sociedad (sociedad civil). Además, la transición post-socialista inevitablemente impone nuevas perspectivas geopolíticas como la Unión Europea, integraciones y el mercado global. El establecimiento del mercado libre implica también nuevos valores y costumbres laborales. Según muchos estudios de opinión pública, que se han hecho constantemente en Serbia desde 2000, el apoyo a la UE nunca ha sido inferior al 50\%. Sin embargo, la gran parte de los ciudadanos de Serbia tiene un entendimiento muy borroso y pesimista de la transición, y sobre todo de las integraciones europeas (A. A., 2009). Por lo tanto, en términos generales, Milo puede ser la personificación de ese $50 \%$ de ciudadanos de Serbia que no acepta esa nueva situación.

La lucha de Milo contra la transición (es decir contra la UE y las integraciones europeas y cambios generales en la sociedad) consiste en diferentes métodos astutos para 'engañar la transición'. Por ejemplo, cuando se implementaron nuevas normas de tráfico más estrictas como parte de una serie de cambios, Milo inventó una camiseta con un cinturón de seguridad cosido en ella con el fin de engañar al policía. Además, cuando la dispensación de los antidepresivos sin receta médica fue prohibida (algo que no ocurrió durante los noventa), Milo comenzó a hacer contrabando de estos fármacos desde China a cambio de víveres. La principal pregunta que hizo fue: “¿Cómo se puede dejar la gente sin bensendin (pastillas antidepresivas populares en Serbia durante los noventa) si lo estuvieron usando durante 10 años?". Él en realidad no podía entender el principal propósito de esa prohibición, y por lo tanto pensaba que alguien le estaba quitando su libertad y su derecho a usar antidepresivos. Sin embargo, una de las aportaciones más famosas de Milo a su lucha contra la transición fue su fuerte y abierto apoyo a la piratería. Concretamente, él rechazaba comprar los CD originales porque creía que gran parte de las ganancias de la industria de los CD se destinaba a los fondos del Pacto de Estabilidad (para el Sudeste de Europa). En vez de eso él compraba sólo los CD búlgaros (piratas) porque hasta su reproductor de CD 'sabía el truco' y quería reproducir sólo la música pirata.

Según estos pocos capítulos presentados brevemente, es obvio que la intención crucial de la serie era jugar con la auto-ironía. Según la opinión del protagonista Zoran Cvijanović, quien interpretó a Milo, el objetivo de la serie y de sus creadores fue combinar en Milo los peores rasgos de la mentalidad serbia. "Nosotros queríamos que la gente se reconociera a sí misma en las características de Milo y queríamos advertir a la gente, de una manera entretenida, que no cediera ante estas características, que no perdiera el control y se convirtiera en - Milo" (Lazić, Intervju - Zoran Cvijanović: Espreso bato).

Por otra parte, como Marko Živković observó, la ironía podría ser un síntoma, pero también un mecanismo defensivo (Živković, 2007: 607). En ese sentido, una cuestión muy importante aquí es: ¿esa ironía presentada en la serie es ironía en verdad? Si queremos analizar este asunto debemos empezar con la intención principal de los creadores de la serie, y compararla después con las reacciones del público. Sólo entonces podemos obtener una idea más clara sobre los efectos que logró la serie. De este modo empleamos el principal paradigma metodológico del estudio antropológico de la cultura popular -que es la relación entre los creadores y los recipientes e insistencia en la comunicación, no en la estética como función primordial de cierta creatividad (Cawelti, 1969; Žikić, 2010). 
En ese aspecto, los niveles relevantes para este análisis son los siguientes. Existen por lo menos tres niveles de comunicación en la serie. El primero representa el contexto de la cadena televisiva B92, que gran parte de la población percibe como una cadena 'misionera' (algunas veces 'traicionera') ${ }^{14}$, mientras que, por otro lado, otro grupo de gente piensa que este es un medio de comunicación objetivo y democrático. El segundo nivel representa los foros de internet donde la gente común intercambia opiniones sobre la serie. ${ }^{15}$ El último nivel consiste en debates públicos entre intelectuales sobre Milo vs. la transición (Milosavljević 2005, Pančić 2004, 2005). Este nivel, de hecho resume los dos niveles anteriores. En cada nivel está muy presente el ambiguo entendimiento de la ironía de la serie. Milo fue originariamente creado como un anti-héroe gracioso y encantador, pero, parece que en cada nivel del análisis existe la percepción de Milo como un héroe, y por lo tanto no como presentación irónica de la mentalidad serbia ni como crítica de la renuencia serbia a la transición. Para aquellos que se identifican con Milo en algunos aspectos, él representa tan sólo una versión cómica de todos aquellos quienes están en contra de la transición. $\mathrm{O}$, en otras palabras, un programa triste y verdadero sobre la fatal decadencia de los ciudadanos de Serbia (Milosavljević, 2005). Así fue cómo la intención inicial de la serie se convirtió sin querer en su oposición, concretamente en anti-ironía. Milo vs. la transición, como Živković indica, es el ejemplo perfecto de ironía indeterminada, "que hace de él un verdadero símbolo de los apuros actuales de Serbia” (Živković, 2007: 603).

Utilizando la terminología de Cawelti, esta serie en un aspecto particular representa una innovación (Cawelti, 1969). Es precisamente su forma. Esta serie introdujo una forma completamente nueva del programa televisivo serbio - una más individualista. La dramatización del monólogo y el abandono del modelo antiguo de la serie familiar, al igual que su transmisión a la hora tardía de la noche son los principales indicadores de la innovación práctica. Pero, todavía una cuestión muy ambigua queda sin respuesta: ¿logró este serial su objetivo intencional? Si no, entonces esta serie de hecho sólo imitaba las percepciones pesimistas de la transición, y tuvo un contraefecto: no cambió la percepción dominante ni tampoco contribuyó, en un sentido más amplio, a los cambios de la mentalidad serbia.

\section{Conclusión}

Las dos series televisivas serbias La Gente Afortunada y Milo vs. la transición han sido presentadas por varias razones importantes. Ambas revelan y reflejan, cada una de diferente manera, dos fases de transición en Serbia y presentan mecanismos de supervivencia de la gente común dentro de ambos períodos de tiempo. En la conclusión nos gustaría reflexionar especialmente sobre un aspecto un poco descuidado que existe debajo del contexto social. Se trata del contexto inter-político que en gran medida influyó en la producción de la realidad presentada en estas series.

La serie La Gente Afortunada fue emitida por primera vez a principios de los noventa en la televisión nacional RTS (Televisión República de Serbia), que en aquél tiempo era completamente controlada por el gobierno de Slobodan Milosević. La representación de la primera transición en la serie no era más que un reflejo humorístico de la realidad social solamente en esos aspectos que no afectaban a la esfera de la realidad política. Debido al 
hecho de que la realidad política era estrictamente controlada y vigilada, la misma fue representada sólo en esos aspectos que no podían poner en peligro la legitimidad política del régimen. Sin embargo, la paradoja está en el hecho de que esa realidad tan limitada, presentada en la serie de hecho correspondía a una realidad fuera de la serie, ya que el activismo político no oficial u oposicional en la vida cotidiana estaba inhibido, se sancionaba de muchas formas.

Milo vs. la transición, por otra parte, representa una crítica de la realidad social de la sociedad serbia donde el pasado y el futuro siempre han estado combatiendo, especialmente desde 2000. El objetivo principal de esta serie era incitar al cambio de esa situación y concientizar a la gente. Como fue el caso de la primera serie, la realidad presentada en Milo vs. la transición también corresponde a la realidad socio-política cotidiana después de 2000. En otras palabras, los factores políticos dominantes como los partidos, las ONG y otras organizaciones civiles en Serbia se confrontan constantemente entre sí por sus diferentes programas políticos y orientaciones de valor, dividiendo a la gente entre aquellos que están 'a favor de las reformas' y 'a favor del Oeste' y aquellos que están 'en contra de las reformas' y 'a favor del Este'. De ese modo la posibilidad de toda continuidad en el ámbito político, social y cultural está debilitándose día tras día.

Considerando todo lo mencionado hasta ahora, las series La Gente Afortunada y Milo vs. la transición podrían representar el verdadero género del realismo social, no sólo por las historias personales, sino por un amplio y profundo traspaso metafórico de los significados socio-políticos de una época a los personajes. En este sentido, uno puede utilizar las series domésticas como una fuente muy conveniente para explorar la sociedad en los niveles manifiestos y latentes de igual manera. Además, incluso cuando no hay suficientes informantes, uno puede estar casi seguro de que podrá observar a los típicos representantes de la sociedad, quienes están interpretados por los diferentes personajes de la serie.

\section{Notas}

1. Este estudio se enmarca en el proyecto número 177026, financiado por el Ministerio de Educación y Ciencia de la República Serbia

2. Las demás repúblicas eran: Bosnia y Herzegovina, Croacia, Eslovenia, Macedonia y Montenegro. Serbia también incluía las provincias autónomas de Kosovo y Voivodina.

3. Este movimiento fue fundado en Belgrado en 1961 por el presidente de Yugoslavia Josip Broz Tito, el presidente de Indonesia Sukarno, el primer ministro de la India Jawaharlal Nehru, el presidente de Ghana Kwame Nkrumah y el presidente de Egipto Gamal Abdel Nasser. Estos líderes abogaban por una postura intermedia de los países en Desarrollo entre los bloques occidental y oriental durante la Guerra Fría.

4. Kosovo declaró su independencia de Serbia en 2008, la cual Serbia oficialmente todavía no reconoce, mientras que, por otra parte, la independencia de Kosovo ha sido reconocida por numerosos países.

5. Los datos y la lista de todas las series de TV serbias y yugoslavas se pueden encontrar en Wikipedia.

6. Las otras dos series eran Složna braća (Los hermanos armoniosos) y Otvorena vrata (La 
puerta abierta). Se puede decir que estas dos series alcanzaron el estatus de culto entre diferentes generaciones del público, lo que confirma el hecho que la gente hasta hoy en día cita a sus personajes favoritos y con mucho gusto evoca las escenas de estos programas de TV.

7. Incluso aquellos que intentaban demostrar que tenían éxito en este nuevo campo no comprendían muy bien el concepto del capitalismo liberal moderno y basaban sus negocios en el sistema de valores característico para la sociedad rural (Matić, 2007).

8. La cadena de televisión B92 fue el primer medio serbio que inspiró el rodaje y la transmisión de los documentales sobre los crímenes ocasionados por diferentes formaciones militares y paramilitares serbias y de las fuerzas especiales del Ejército Popular Yugoslavo (JNA) durante la guerra en Bosnia y Croacia. Gran parte de los demás documentales trataban los temas como el régimen de Milošević, protestas estudiantiles y civiles, el embargo económico y la pobreza masiva durante los noventa.

9. Zoran Đinđić fue el primer ministro del primer gobierno democrático serbio desde 2001 hasta 2003. El ex comandante de las fuerzas militares especiales "La Unidad de las Operaciones Especiales" Milorad Ulemek, quien estuvo al mando de esta unidad durante el régimen de Slobodan Milošević, fue directamente envuelto en el asesinato del primer ministro. Los motivos principales para el asesinato y golpe de estado eran los políticos reformistas y de orientación pro-occidental por los que Zoran Đinđić abogaba, como también su lucha contra las estructuras criminales que estaban muy arraigadas en la sociedad serbia durante el régimen de Slobodan Milošević.

10. "El fuerte euroescepticismo es donde hay oposición a la UE y a la integración europea basada en fuertes principios y por tanto se puede notar en los partidos que piensan que sus países deberían desistir del ingreso, o cuyas políticas hacia UE equivalen a estar en contra del entero proyecto de la integración europea como se concibe en la actualidad." (Taggart and Szczerbiak, 2002: 7).

11. Y de esta manera estaban cuestionando y minimizando la participación del régimen de Slobodan Milošević en la política de limpieza étnica y devastación material durante las guerras en la región de la ex Yugoslavia.

12. El famoso actor serbio Zoran Cvijanović, quien hizo famoso a Milo de Čubura, promocionó, en la muy reconocible manera de gesticulación de Milo, varios productos - incluso un banco. Es muy interesante observar cómo se transmitió su personaje de la serie al campo de marketing con el fin de convencer a los consumidores. La idea del comercial era convertir a Milo de un gran escéptico a un buen consumidor. Y eso, de hecho, fue un uso muy inteligente de un famoso personaje de TV. Desafortunadamente, este aspecto de cambio del personaje desde un escéptico hasta un persuasor no se puede elaborar aquí debido a la limitación del trabajo.

13. En los últimos capítulos de Milo vs. la transición emitidos por B92 en 2007, el director y los guionistas introdujeron a varios personajes nuevos como la mujer de Milo, su mejor amiga, y también el vecino y el padre de Milo, quienes eran sus principales partidarios y ayudantes en su lucha contra la transición.

14. El célebre director Emir Kusturica, según un reportaje de prensa, ha prohibido la transmisión de la cadena B92 en su complejo turístico de lujo conocido como "Drvengrad" en la montaña Tara, porque piensa que esta cadena de televisión constantemente 
difunde mentiras sobre Serbia en el país y en el extranjero (http://www.pressonline.rs/sr/ vesti/vesti_dana/story/891/KUSTURICA+ZABRANIO+B92!.html).

15. Hay varios foros útiles sobre esta serie, por ejemplo: http://www.elitemadzone.org/ t53307-0\#342724, http://forum.burek.com/mile-vs-tranzicija-novi-mile-stara-borba-t26 2133.html, http://www.moviestation.org/movie/39416/<b $>$ Mile $</$ b $>$ _vs_tranzicija.

\section{Bibliografía}

A. A. Šta nam znači EU. Politika, (Decembar 27, 2009).

AGB Nielsen Media Research: http://agbnmr.com/whereweare/dynPage.asp?lang=local\& id $=354 \&$ country $=$ Serbia

Antonić, Slobodan. (2004). Društvena osnova i sadašnji pokušaj modernizacije. In: Anđelka Milić (ed.), Društvena transformacija i strategije društvenih grupa: svakodnevica Srbije na početku milenijuma. Beograd: Institut za sociološka istraživanja Filozofskog fakulteta.

Backes, Uwe and Patrick Moreau. (2008). Communist and Post-Communist Parties in Europe. Gottingen: Vandenhoeck and Ruprecht.

Cawelti, J. G. (1969). The Concept of Formula in the Study of Popular Culture. Journal of Popular Culture, Vol. 3, No. 3, 381 - 390.

Đurković, M. (2005). Prva Petoletka: Domaće televizijske serije i transformacija sistema vrednosti u tranziciji. Sociološki pregled, Vol.XXXIX, No.4, Institut za evropske studije, 357-381.

Fiske, J. (2001). Television Culture. Taylor \& Francis e-Library.

Jordan, M. (1981). Realism and Convention. In: R. Dyer, C. Geraghty, M. Jordan, T. Lovell, R. Paterson and J. Stewart (eds.), Coronation Street. London: British Film Institute, 27-39. Kopecky, P. and Cas Mudde. (2002). The Two Sides of Euroscepticism Party Positions on European Integration in East Central Europe. European Union Politics, Vol. 3. London: Sage Publications. 297-326.

Kovačević, I. (2006). Tranziciona legenda o dobitnicima. Etnoantropološki problemi. Vol. 1, Sv. 2, 11-25.

Lazić, J. (January 27, 2005). Intervju - Zoran Cvijanović: Espreso bato. Vreme, 734.

Retrieved August 20, 2011 from http://www.vreme.com/cms/view.php?id=404318

Lazić, Mladen. Cvejić, Slobodan. (2004). Promene društvene strukture u Srbiji: slučaj blokirane post-socijalističke transformacije. In: Anđelka Milić (ed.), Društvena transformacija i strategije društvenih grupa: svakodnevica Srbije na početku trećeg milenijuma. Beograd: Institut za sociološka istraživanja Filozofskog fakulteta, 39-70.

Lohof, B. A. (1972). Popular Culture: The Journal and the State of the Study. Journal of Popular Culture, Vol. 6, No. 3, 453 - 462.

Matić, M. (2007). Privatno preduzetništvo u savremenoj Srbiji. Antropologija, No. 3, 86-96. McLuhan, M. (1994). Understanding Media: The Extensions of Man, Boston: The MIT Press, MA (Reprint Edition).

Milosavljević, Dragan. (2005). Mile, tranzicija. Manipulacija: Kriva ogledala Teofila Pančića. Nova srpska politička misao. No. 106. Retrieved August 20, 2011 from http://www.starisajt.nspm.rs/komentari2005/2005_dm_mile_1.htm 
Mihailović, Srećko. (2010). Priča o tranziciji ili naracija o našim beskrajnim menama. In: Kako građani Srbije vide tranziciju. Istraživanje javnog mnenja tranzicije. Službeni glasnik. 7-29.

Naumović, Slobodan. (2006). On the Heaviness of Feathers, or What Has Culture Got to do With the Failure to Establish an Organic Poultry Production Business in Contemporary Serbia? Etnoantropološki problemi, Vol.1, No. 1, 103-124.

Pančić, T. (Januar 15, 2004). Mile sa Čubure u Vladi. Vreme, 680. Retrieved August 20, 2011 from http://www.vreme.com/cms/view.php?id=364193

Mile protiv tranzicije - koplje u trnje: Nacionalna klasa. Vreme, 734, Januar 27, 2005. Retrieved August 20, 2011 from http://www.vreme.com/cms/view.php?id=404318

Ristić, I. (2008). The Socialist Party of Serbia”. Uwe Backes and Patrick Moreau (eds.) Communist and Post-Communist Parties in Europe. Gottingen: Vandenhoeck and Ruprecht. 343-371.

Spitulnik, D. (1993). Anthropology and Mass Media, Annual Review of Anthropology, Vol. $22,293-315$.

Taggart, P. and Szczerbiak, A. (2002). The Party Politics of Euroscepticism in EU Member and Candidate States. SEI Working Paper No 51 (also Opposing Europe Research Network Working Paper No 6) Sussex: Sussex European Institute.

Verdery, K. (1998). Transnationalism, Nationalism, Citizenship, and Property: Eastern Europe Since 1989. In: American Ethnologist. Vol. 25, No. 2. Blackwell Publishing. 291- 306

Zivkovic, M. (2007). Mile vs Transition - a Perfect Informant in the Slushy Swamp of Serbian Politics. Social Identities, Vol. 13, No. 5. Routledge, 597-610.

Žikić, Bojan. (2010). Antropološko proučavanje popularne culture. Etnoantropološki problemi, Vol. 5, No. 2, 17-39.

(2007). Ljudi (koji nisu sasvim) kao mi. Kulturna konceptualizacija pojma privatnik u Srbiji. In: Vladimir Ribić (ed.) Antropologija postsocijalizma, Beograd: Odeljenje za etnologiju i antropologiju Filozofskog fakulteta i Srpski genealoški centar, Etnološka biblioteka knj. 34, 52-74.

Summary: This study aims to examine how the new social phenomenon and value orientation, which has been a result of the transition process (from 1989-to present), are reflected in the Serbian TV series production. As the particularity of the post-socialist transformation has been developed in two phases in Serbian society, we have chosen two television series for this analysis: Sre ni ljudi (Lucky People) and Mile protiv tranzicije (Milo Vs. Transition). The first one belongs to the first transition period (1989-2000), while the second can be placed in the context of the so-called second transition (2000 - to present). The first case describes the beginning of the social and economic transformation, that means the collapse of public enterprises and state signaling its privatization and the emergence of private employers. On the other hand, the second case makes a parody of how the extensive conglomeration of certain political and social relations have changed and the values that represent the transition indicators (establishment of liberal democracy, 
political correctness, the multiplication of NGOs , integration into the EU). We decided to analyze TV series becuse them describe several different phases of the entire period of the post-Socialist transformation. Focusing on this, we believe that we can analyze how they reflect and presents the key consequences of different phases of the transition in one of the most important media of popular culture today.

Key words: Serbian society - transition - transition phases - TV series - value system.

Resumo: Nossa intenção neste estudo é examinar como o novo fenômeno social e a orientação de valores, conseqüência do processo de transição (desde 1989 até hoje), estão refletidos na produção televisiva de séries (telenovelas) domésticas na sociedade sérvia. Em relação à particularidade da transformação post-socialista que se desenvolveu em duas fases na sociedade sérvia, se escolheram duas séries televisivas para este análise: Sre ni ljudi (As pessoas afortunadas) y Mile protiv tranzicije (Milo vs. a transição). A primeira pertence ao período da primeira transição (1989-2000), entretanto a segunda pode-se situar no contexto da chamada segunda transição (2000 - atualidade). A primeira série descreve o inicio da transformação social e econômica, ou seja, o colapso das empresas públicas e estatais, a privatização e aparição dos empresários privados. A segunda faz uma paródia da extensa aglomeração de determinadas relações políticas e sociais que mudaram e dos valores que representam os indicadores da transição (estabelecimento da democracia liberal, a correção política a multiplicação das ONG, a integração na UE). A razão principal da seleção destas séries de TV para a análise é porque descrevem diversos aspectos de diferentes fases do período completo da transformação post - socialista. Enfocando-nos nisso, achamos que podemos analisar como se refletem e se apresentam as conseqüências dominantes de diferentes fases da transição em um dos meios de comunicação mais importantes da cultura popular atual.

Palavras chave: fases de transição - séries de televisão - sistema de valores - sociedade sérvia - transição. 